\title{
Metabolism of Gestobutanoil, a Novel Bmo of Progestin Group
}

DOI: $10.17691 /$ stm2019,11.3.06

Received December 18, 2018

E.S. Stepanova, Head of Bioanalytical Mass Spectrometry Laboratory, Center for Collective Use

(Scientific and Educational Center)',

L.M. Makarenkova, Analytical Pharmacist, Bioanalytical Mass Spectrometry Laboratory,

Center for Collective Use (Scientific and Educational Center) $)^{1}$;

V.V. Chistyakov, DSc, Director of the Center for Collective Use (Scientific and Educational Center $)^{1}$;

T.A. Fedotcheva, MD, DSc, Senior Researcher, Research Laboratory of Molecular Pharmacology2;

Chief Researcher, Metabolomics Laboratory ${ }^{3}$;

V.A. Parshin, MD, PhD, Leading Researcher, Research Laboratory of Molecular Pharmacology2;

N.L. Shimanovsky, MD, DSc, Corresponding Member of the Russian Academy of Sciences,

Head of the Department of Molecular Pharmacology and Radiobiology named after Academician P.V. Sergeev ${ }^{2}$

Peoples Friendship University of Russia, 6 Miklukho-Maklaya St., Moscow, 117198, Russia;

2Pirogov Russian National Research Medical University, 1 Ostrovitianov St., Moscow, 117997, Russia;

${ }^{3}$ All-Russian Research Institute of Medicinal and Aromatic Plants, 7 Grin St., Moscow, 117216, Russia

The aim of the study is to evaluate the metabolism of progestin drug Gestobutanoil in the experiment with administration of tablet dosage form containing Gestobutanoil (2 mg), to experimental animals (rats and rabbits).

Materials and Methods. There was performed analysis of biomatrix obtained from different species of animals: female rats weighing $200.0 \pm 60.0 \mathrm{~g}$ and female rabbits weighing $3.0 \pm 0.2 \mathrm{~kg}$, which were administered different doses of the drug, single or multiple. Metabolites were identified using high performance liquid chromatography-mass spectrometry (HPLC-MS).

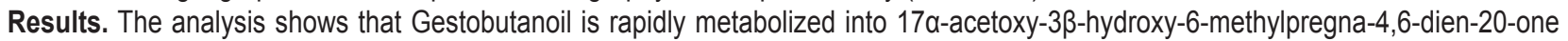
(AMP-17) and 17-hydroxy-6-methylpregna-1,4-diene-3,20-dione in the form of acetate (MA). The steroid core of Gestobutanoil has the butyric acid radical in the $3 \beta$ position. This radical cleavage underlies biotransformation of Gestobutanoil. The obtained pharmacokinetic parameters for metabolites have demonstrated that Gestobutanoil has a stepwise nature of metabolism: the time to reach the maximum concentration of AMP-17 is $1.5 \mathrm{~h}, \mathrm{MA}-3 \mathrm{~h}$. Also AMP-17 proves to penetrate into the peripheral tissues better than MA.

Conclusion. The data obtained speak of a unique, different from other gestagens, metabolism of Gestobutanoil. Unlike the known progestogen medroxyprogesterone acetate whose main route of transformation is hydroxylation of the steroid nucleus of the molecule with rather high bioavailability in an unchanged state, Gestobutanoil shows rapid biotransformation into metabolites AMP-17 and MA manifesting their own gestagenic activity with release of butyric acid, which, in turn, may produce a calming effect on the central nervous system.

Key words: metabolism; pharmacokinetics; gestagens; Gestobutanoil; HPLC-MS; steroids.

\section{Introduction}

The object of the study was a novel drug in tablet dosage form based on a steroid compound Gestobutanoil (17a-acetoxy-3ß-oxy-6-methylpregna-4,6-dien-20-one in the form of butanoate), for hormone replacement therapy in gestagen deficiency, particularly, its metabolism in experimental animals - rats and rabbits.

The drug and its active substance were developed at Pirogov Russian National Research Medical University to correct gestagen deficiency in women. Previously, Gestobutanoil was found to have high specific pharmacological activity, 102 and 20 times superior to comparator drugs - progesterone and levonorgestrel, respectively [1, 2].

Acute, chronic and specific toxicity of Gestobutanoil tablets of $2 \mathrm{mg}$ was investigated, which allowed classifying the developed low-toxic drug into the category of toxicity class 4 substances [3].

An essential component of preclinical research of novel drugs is also studying their metabolism: qualitative and quantitative analysis of biotransformation products of pharmacological agents, evaluation of interspecific differences in metabolism [4].

The aim of the study is to evaluate the metabolism of a finished dosage form of progestational steroid drug Gestobutanoil in biological fluids of rats and rabbits after administration of Gestobutanoil tablets of $2 \mathrm{mg}$.

\section{Materials and Methods}

The study was carried out with the use of Gestobutanoil in tablets containing $2 \mathrm{mg}$ of butyl ester $17 \alpha$-acetoxy-3 $\beta$-oxy-6-methylpregna-4,6-dien-20-one

Corresponding author: Tatiana A. Fedotcheva, e-mail: tfedotcheva@mail.ru 
as an active pharmaceutical substance, polyvinyl alcohol (4 mg) and PROSOLV® EASYTab SP (94 mg) as auxiliary substances, developed at Pirogov Russian National Research Medical University (project CPD, state registration number: AAAA-A17-117052950002-8).

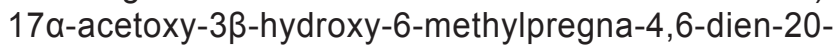
one (AMP-17) substance was synthesized at the Federal Research Centre "Bioengineering" of the Russian Academy of Sciences. 17-hydroxy-6-methylpregna-1,4diene-3,20-dione substance in the form of acetate (MA) was produced by Sigma (USA).

The animals were administered powdered tablets as a suspension in a $0.5 \%$ solution of carboxymethylcellulose (CMC). A glass beaker was filled with $2 \mathrm{~g}$ of $\mathrm{CMC}$ (Merck, Germany), $400 \mathrm{ml}$ of hot $\left(60-70^{\circ} \mathrm{C}\right)$ distilled water was added to obtain a homogeneous $0.5 \% \mathrm{CMC}$ gel with prolonged stirring on a magnetic stirrer $\mathrm{RH}$ basic (IKA, Germany). The suspension of tablets was prepared in a porcelain pounder by triturating tablets with a small amount of CMC gel and $1 \mathrm{ml}$ of Twin- 80 polysorbate. The suspension volume was adjusted to the required by mixing the contents of the pounder and CMC gel in a glass beaker with a magnetic stirrer.

Metabolite identification and assay were performed on a high performance liquid chromatograph Ultimate 3000 (Dionex, Germany) with mass detector MicrOTOF-Q II (Bruker, Germany) using the method described in work [5].

Blood serum was obtained from two types of experimental animals: female rats weighing $200.0 \pm 60.0 \mathrm{~g}$ and female rabbits weighing $3.0 \pm 0.2 \mathrm{~kg}$ (Stolbovaya breeding nursery, Chekhov, Moscow region). Basic conditions of animal care and management complied with the Guidelines CP 2.2.1.3218-14 dated 29.08.2014 No.51, GOST 33044-2014 and the Order of the Ministry for Public Health and Social Development of the Russian Federation No.199n dated 01.04.2016.

Rats and rabbits were deprived of food prior to drug administration (18 $\mathrm{h}$ before the experiment). Blood samples were collected from rats during decapitation, rabbit blood samples were taken from the auricular vein through a catheter. Serum was obtained by centrifugation of the blood at $3000 \mathrm{rpm}$ for $5 \mathrm{~min}$ in the centrifuge MiniSpin (Eppendorf, Germany).
Based on pharmacokinetic data of the comparator drug medroxyprogesterone acetate, similar in chemical structure and pharmacological properties [6,7], it was decided to consider $25 \mathrm{mg} / \mathrm{kg}$ of Gestobutanoil as the main provisional reference dose. In preliminary experiments, only metabolites AMP-17 and MA were found in the blood serum of rats, receiving Gestobutanoil in a dose of $25 \mathrm{mg} / \mathrm{kg}$. Analytical method with $10 \mathrm{ng} / \mathrm{ml}$ quantification limit for Gestobutanoil failed to detect the drug in rat blood serum. In order to study the metabolism in detail and the possibility to obtain the kinetics of Gestobutanoil per se, we have taken an increase in doses: rats were administered 50, 100, and $250 \mathrm{mg} /$ $\mathrm{kg}$, rabbits $-50 \mathrm{mg} / \mathrm{kg}$. The selected doses were no more than $L_{50}$ of Gestobutanoil, previously defined as $>5 \mathrm{~g} / \mathrm{kg}$ [3].

\section{Results and Discussion}

Analysis of biomatrix from different animal species showed that Gestobutanoil underwent rapid biotransformation forming metabolites AMP-17 and MA. This biotransformation pathway is ensured by the presence of a butyric acid radical in the Gestobutanoil molecule at position $3 \beta$, which is easily cleaved. No Gestobutanoil was detected in the serum of rats and rabbits even at the first time point $(0.25 \mathrm{~h}, 0.75 \mathrm{~h})$ after administration of high doses. Pharmacokinetics of the drug was studied indirectly by its metabolites. Figure 1 shows the structural formula of Gestobutanoil and its metabolites AMP-17 and MA.

Pharmacokinetics of Gestobutanoil in rat blood serum after a single administration. Figure 2 shows pharmacokinetic curves of AMP-17 and MA metabolites in rat serum, obtained after a single oral administration of Gestobutanoil in doses of 50, 100, and $250 \mathrm{mg} / \mathrm{kg}$.

These curves clearly demonstrate that peak serum concentration of the metabolite AMP-17 ( $T_{\max }=0.25$ $1.5 \mathrm{~h}$ ) occurs faster than for $M A$ with $T_{\max }=1.5-6 \mathrm{~h}$ after administration of Gestobutanoil. Assessment of linearity of pharmacokinetics showed that the maximum concentration of metabolites $\left(\mathrm{C}_{\max }\right)$ was not Gestobutanoil dose dependent. $C_{\max }$ values for AMP-17 were 390.4,

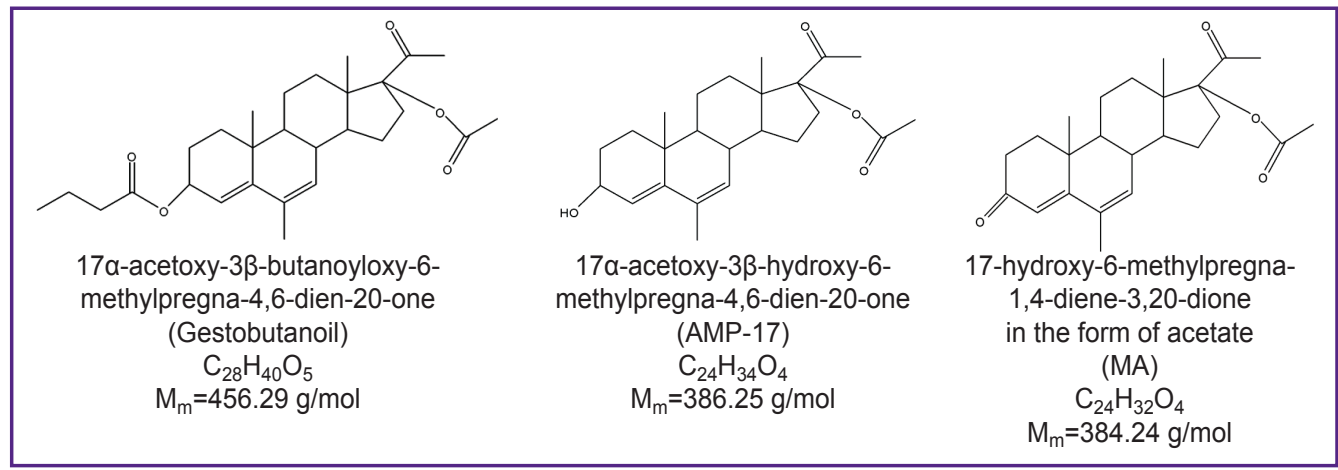

Figure 1. Structural formulas of analytes 


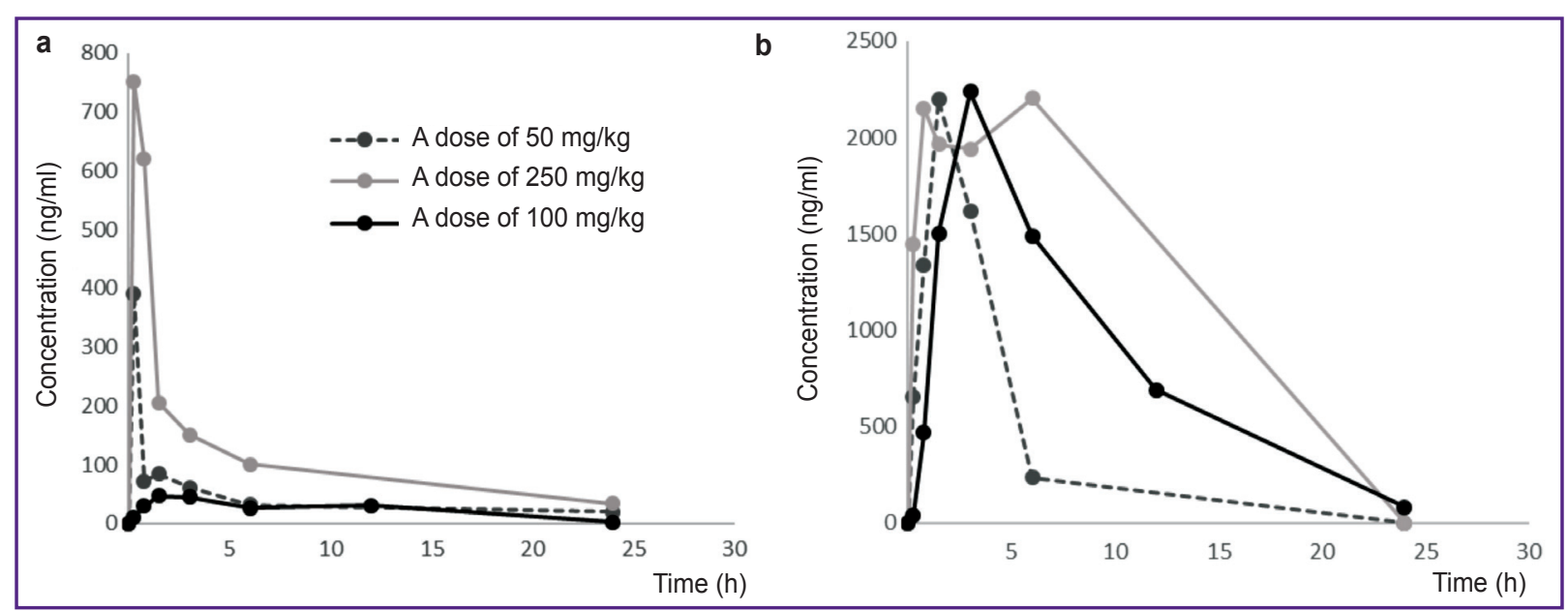

Figure 2. Pharmacokinetic curves of metabolites AMP-17 (a) and MA (b) at different doses of Gestobutanoil administered to rats orally as a single dose

47.0, and $750.9 \mathrm{ng} / \mathrm{ml}$ for doses of 50,100 , and $250 \mathrm{mg} / \mathrm{kg}$, respectively. Maximum MA concentrations at different doses were almost the same: 2196.0, 2238.2, and $2205.0 \mathrm{ng} / \mathrm{ml}$ for doses of 50,100 , and $250 \mathrm{mg} / \mathrm{kg}$, respectively. The drug dose of $250 \mathrm{mg} / \mathrm{kg}$ provides a plateau of high MA concentration in animal blood serum ranging 0.75 to $6 \mathrm{~h}$, which indicates the effect of enzyme saturation with the substrate, at which the maximum rate of biotransformation reaction is achieved.

Table 1

Pharmacokinetic parameters of metabolites AMP-17 and MA after oral single administration of Gestobutanoil tablets suspension to different animal species

\begin{tabular}{|c|c|c|c|c|}
\hline Parameter & $\begin{array}{l}\text { Rats, a dose } \\
\text { of } 50 \mathrm{mg} / \mathrm{kg}\end{array}$ & $\begin{array}{l}\text { Rats, a dose } \\
\text { of } 100 \mathrm{mg} / \mathrm{kg}\end{array}$ & $\begin{array}{l}\text { Rats, a dose } \\
\text { of } 250 \mathrm{mg} / \mathrm{kg}\end{array}$ & $\begin{array}{c}\text { Rabbits, a dose } \\
\text { of } 50 \mathrm{mg} / \mathrm{kg}\end{array}$ \\
\hline \multicolumn{5}{|c|}{ AMP-17 } \\
\hline $\mathrm{AUC}_{0-24}(\mathrm{ng} / \mathrm{ml} / \mathrm{h})$ & 938.7 & 590.9 & 5133.9 & 102.4 \\
\hline $\mathrm{AUC}_{0-\infty}(\mathrm{ng} / \mathrm{ml} / \mathrm{h})$ & 1370.9 & 612.1 & 5637.8 & 190.7 \\
\hline $\mathrm{C}_{\max }(\mathrm{ng} / \mathrm{ml})$ & 390.4 & 47.0 & 7508.9 & 22.46 \\
\hline $\mathrm{T}_{\max }(\mathrm{h})$ & 0.25 & 1.5 & 0.25 & 0.25 \\
\hline $\mathrm{CL}(\mathrm{L} / \mathrm{h})$ & 14.6 & 32.67 & 3.5 & 104.9 \\
\hline $\mathrm{k}_{\mathrm{el}}(1 / \mathrm{h})^{\prime}$ & 0.044 & 0.138 & 0.067 & 0.141 \\
\hline$T_{1 / 2}(h)$ & 15.7 & 5.0 & 10.4 & 4.91 \\
\hline MRT (h) & 19.8 & 8.9 & 6.3 & 7.54 \\
\hline $\mathrm{Vd}(\mathrm{L})$ & 330.9 & 236.5 & 53.1 & 743.0 \\
\hline \multicolumn{5}{|c|}{ MA } \\
\hline $\mathrm{AUC}_{0-24}(\mathrm{ng} / \mathrm{m} / \mathrm{h})$ & $11,580.0$ & $20,444.3$ & $35,669.6$ & 4119.2 \\
\hline $\mathrm{AUC}_{0-\infty}(\mathrm{ng} / \mathrm{ml} / \mathrm{h})$ & $14,451.6$ & $20,978.4$ & $41,743.7$ & 4897.4 \\
\hline $\mathrm{C}_{\max }(\mathrm{ng} / \mathrm{ml})$ & 2196.0 & 2238.2 & 2205.0 & 413.56 \\
\hline $\mathrm{T}_{\max }(\mathrm{h})$ & 1.5 & 3.0 & 6.0 & 1.5 \\
\hline $\mathrm{CL}(\mathrm{L} / \mathrm{h})$ & 1.4 & 0.95 & 0.48 & 4.08 \\
\hline $\mathrm{k}_{\mathrm{el}}(1 / \mathrm{h})$ & 0.065 & 0.163 & 0.076 & 0.075 \\
\hline$T_{1 / 2}(h)$ & 10.7 & 4.3 & 9.1 & 9.21 \\
\hline MRT (h) & 13.1 & 7.7 & 11.5 & 12.08 \\
\hline $\mathrm{Vd}(\mathrm{L})$ & 21.3 & 5.9 & 6.3 & 54.3 \\
\hline
\end{tabular}

Table 1 shows the calculated pharmacokinetic parameters of AMP-17 and MA metabolites in rats at three doses. The area under the curve (AUC) characterizing bioavailability calculated for MA has linear dependence on the dose of Gestobutanoil administered in the dose range of $50-250 \mathrm{mg} / \mathrm{kg}$. The bioavailability (AUC) of AMP-17, just like $C_{\max }$, is not dose-dependent, which suggests strong influence of external factors on this route of Gestobutanoil biotransformation.

AMP-17 metabolite compared to MA is characterized by larger volume of distribution $(V d)$, which is likely to indicate its more active penetration into the peripheral tissues and intensive metabolism of AMP-17 molecule. Half-life periods $\left(T_{1 / 2}\right)$ of the two metabolites are almost the same and vary within 5.0 $15.7 \mathrm{~h}$ for AMP-17 and 4.3-10.7 $\mathrm{h}$ for MA. Elimination rate constants $\left(\mathrm{k}_{\mathrm{el}}\right)$ for metabolites are $0.044-0.138 \mathrm{~h}^{-1}$ for AMP-17 and 0.065$0.163 \mathrm{~h}^{-1}$ for MA. AMP-17 clearance (CL) has large dispersion and equals 14.6, 32.67, and $3.5 \mathrm{~L} / \mathrm{h}$ for doses of 50,100 , and $250 \mathrm{mg} / \mathrm{kg}$, respectively. Metabolite MA clearance is 1.4 , 0.95 , and $0.48 \mathrm{~L} / \mathrm{h}$ for doses of 50,100 , and $250 \mathrm{mg} / \mathrm{kg}$, respectively. Mean residence time (MRT) is 6.3-19.8 $\mathrm{h}$ for AMP-17 and 7.7$13.1 \mathrm{~h}$ for MA.

Disproportionate increase in $\mathrm{C}_{\max }$ values with increasing dose of Gestobutanoil and dependence of pharmacokinetic parameters such as $V d, k_{e l}, C L, T_{1 / 2}$, and MRT on the dose suggest nonlinear pharmacokinetic nature of Gestobutanoil metabolites.

Pharmacokinetics of Gestobutanoil after a single administration to rabbits. According to the preclinical guidelines [4], the study of pharmacokinetics includes the comparison of pharmacokinetics in different animal species 


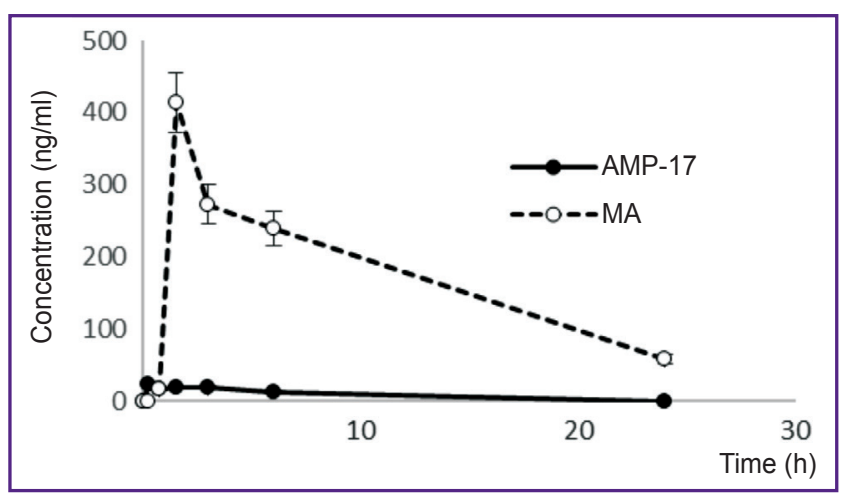

Figure 3. Concentration of metabolites in rabbit blood serum after a single oral administration of Gestobutanoil at a dose of $50 \mathrm{mg} / \mathrm{kg}$

at the same dose. The selected dose of $50 \mathrm{mg} / \mathrm{kg}$ for rabbits was sufficient in terms of analytical method sensitivity to study the differences in pharmacokinetics in rats and rabbits. Since pharmacokinetics at a dose of $50 \mathrm{mg} / \mathrm{kg}$ was described for rats (see Table 1), the same dose was chosen for rabbits.

Figure 3 shows pharmacokinetic curves of metabolites AMP-17 and MA detected in the serum of rabbits administered Gestobutanoil at a single oral dose of $50 \mathrm{mg} / \mathrm{kg}$.

It is evident from Figure 3 that $C_{\max }$ of AMP-17 in rabbit blood serum is $22.5 \mathrm{ng} / \mathrm{ml}$, MA $\mathrm{C}_{\max }-413.6 \mathrm{ng} /$ $\mathrm{ml}$. Table 1 presents the calculated pharmacokinetic parameters of metabolites AMP-17 and MA.

AMP-17 has large volume of distribution ( $\mathrm{Vd}=743.0 \mathrm{~L})$ as compared to MA, in which $\mathrm{Vd}=54.3 \mathrm{~L}$. In rabbits, $\mathrm{k}_{\text {el }}$ values equal 0.141 and $0.075 \mathrm{~h}^{-1}$ for AMP-17 and MA, respectively. Clearance is $104.9 \mathrm{~L} / \mathrm{h}$ for AMP-17 and 4.08 L/h for MA. $T_{1 / 2}$ is 4.91 for AMP-17 and 9.21 for MA; MRT is 7.54 and 12.08 for AMP-17 and MA, respectively.

Presented data allow for a conclusion about the presence of general patterns in metabolism of Gestobutanoil in rats and rabbits. The differences in pharmacokinetics in the compared animal species are present at the level of bioavailability of the identified metabolites. The increase in animal body weight leads to the decrease in $A U C$ and $C_{\max }$ from species to species. However, it is impossible to speak definitely about the decrease of Gestobutanoil bioavailability judging by its metabolites. It should be also taken into account that the decrease in bioavailability does not necessarily suggest the decrease in drug efficacy, since the decrease in the total amount of circulating substance in blood does not prove a decrease in the amount of substance at the site of action or at the target organ.

The time of reaching the maximum concentration correlated in rats and rabbits only for one dose $-50 \mathrm{mg} /$ $\mathrm{kg}$. At the same time, $T_{\max }$ AMP-17 was always less than $T_{\max } M A$, both in rats and rabbits. The increase in $C L$ and $\mathrm{Vd}$, is likely to be associated only with the increase in body weight of the animals.
Parameters characterizing elimination of AMP-17 from the body are not reproduced in different species at different doses, which indicates the nonlinear nature of metabolite pharmacokinetics.

In case of MA, pharmacokinetic parameters for the dose of $50 \mathrm{mg} / \mathrm{kg}$ show that elimination occurs equally in rats and rabbits. There are almost no interspecific differences in MA pharmacokinetics.

Multiple-doses pharmacokinetics of Gestobutanoil in rats. Though in previous studies the pharmacokinetics of Gestobutanoil was described only through its metabolites, the multiple-doses studies must be carried out. There was no need to investigate more than one dose. The multiple-doses studies were carried out on rats with the dose of $50 \mathrm{mg} / \mathrm{kg}$. The dose was chosen to avoid potential toxic effects due to possible accumulation of the substance and its metabolites in the body.

Pharmacokinetic curves (Figure 4) of metabolites AMP-17 and MA represented by average concentrations found in blood serum of rats administered Gestobutanoil repeatedly for 5 days at a dose of $50 \mathrm{mg} / \mathrm{kg}$ show kinetic dependences obtained on day 5 of the experiment.

After multiple administration, kinetic curves of metabolites have a similar shape to the curves obtained at a single administration (see Figure 2). Based on that, we can suggest that there is no effect of accumulating Gestobutanoil substance and its metabolites. Time of reaching the maximum concentration is 2 and $3 \mathrm{~h}$ for AMP-17 and MA after Gestobutanoil administration. The maximum concentrations of AMP-17 and MA are 15.1 and $237.2 \mathrm{ng} / \mathrm{ml}$, respectively, which is significantly less than in the experiment with a single administration of the same dose.

Comparison of AUC values of metabolites (Table 2) also showed their decrease compared to the data in Table 1. This, evidently, indicates saturation effect of enzyme systems responsible for biotransformation of Gestobutanoil administered repeatedly as compared to

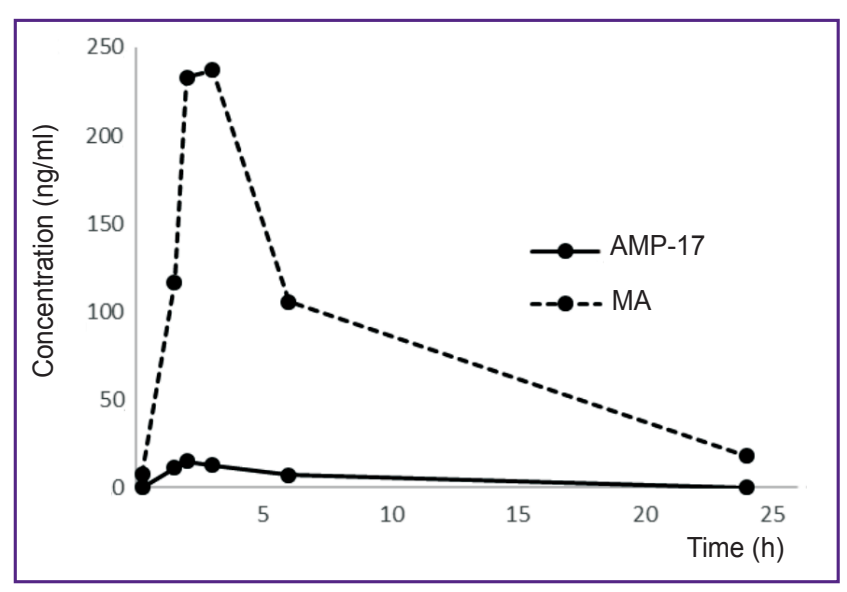

Figure 4. Concentration of AMP-17 and MA in rat serum after multiple oral administration of Gestobutanoil at a dose of $50 \mathrm{mg} / \mathrm{kg}$ 
Table 2

\begin{tabular}{|c|c|c|}
\hline \multicolumn{3}{|c|}{$\begin{array}{l}\text { Pharmacokinetic parameters } \\
\text { of metabolites AMP-17 and MA } \\
\text { after multiple oral administration } \\
\text { of Gestobutanoil tablets suspension } \\
\text { to rats at a dose of } 50 \mathrm{mg} / \mathrm{kg}\end{array}$} \\
\hline Parameter & AMP-17 & MA \\
\hline $\mathrm{AUC}_{0-\infty}(\mathrm{ng} / \mathrm{ml} / \mathrm{h})$ & 58.88 & 2029.94 \\
\hline$A \cup C_{0-\infty}(n g / m l / h)$ & 96.29 & 2138.04 \\
\hline $\mathrm{C}_{\max }(\mathrm{ng} / \mathrm{ml})$ & $15.1 \pm 2.2$ & $237.2 \pm 16.3$ \\
\hline $\mathrm{T}_{\max }(\mathrm{h})$ & 2 & 3 \\
\hline $\mathrm{CL}(\mathrm{L} / \mathrm{h})$ & 207.71 & 9.16 \\
\hline$k_{\text {el }}(1 / h)$ & 0.191 & 0.114 \\
\hline$T_{1 / 2}(h)$ & 3.6 & 6.1 \\
\hline MRT (h) & 6.24 & 8.04 \\
\hline $\operatorname{Vd}(L)$ & 1090.6 & 80.3 \\
\hline
\end{tabular}

that after a single dose. By contrast, Vd values of each metabolite increased in the experiment with multiple administration of Gestobutanoil: they amounted to 1090.6 and $80.3 \mathrm{~L}$ for AMP-17 and MA, respectively. $\mathrm{CL}$ increased with the increase of the $\mathrm{Vd}$. When Gestobutanoil was administered repeatedly, it amounted to $207.71 \mathrm{~L} / \mathrm{h}$ for AMP-17 and $9.16 \mathrm{~L} / \mathrm{h}$ for MA.

Actually, there is no change in kinetic parameters describing excretion of metabolites from the body when changing single dosing regimen to multiple administration. Half-elimination period was $3.6 \mathrm{~h}$ for AMP-17, $6.1 \mathrm{~h}$ for MA. In multiple administration experiment, elimination rate constant was $0.191 \mathrm{~h}^{-1}$ for AMP-17 and $0.114 \mathrm{~h}^{-1}$ for MA.

Metabolism studies of a novel gestagen steroid drug in tablet dosage form containing $2 \mathrm{mg}$ of Gestobutanoil in vivo in rabbits and rats using high performance liquid chromatography-mass spectrometry method show that Gestobutanoil is rapidly metabolized forming two metabolites AMP-17 and MA. Pharmacokinetic parameters for metabolites indicate that Gestobutanoil has a stepwise nature of metabolism: the time to reach the maximum concentration of AMP-17 is $1.5 \mathrm{~h}$ and MA $-3 \mathrm{~h}$. Compared with MA, the metabolite AMP17 penetrates better into the peripheral tissues. It has been established that pharmacokinetics of the metabolites is nonlinear. Enzyme saturation forms a plateau on MA pharmacokinetic curve when high doses of Gestobutanoil are administered.

There were no interspecific significant differences in the Gestobutanoil metabolism in rats and rabbits. At the same doses, the decreases in $C_{\max }$ and AUC were observed in rabbits compared to rats.

Pharmacokinetic parameters show no effect of accumulation and deposition of metabolites after multiple-doses administration of Gestobutanoil to rats for 5 days. However, the decrease of $A \cup C$ and $C_{\max }$ indicates a slowdown in metabolism, which implies the presence of enzyme saturation effect.

\section{Conclusion}

The data suggests that the metabolism of Gestobutanoil has a unique path, completely different from other gestagens. Unlike the known medroxyprogesterone acetate whose main route of transformation is hydroxylation of the steroid nucleus of the molecule $[8,9]$ with rather high bioavailability in an unchanged state [6], Gestobutanoil shows rapid biotransformation into metabolites AMP-17 and MA manifesting their own gestagenic activity [10], with release of butyric acid, which, in turn, may produce a calming effect on the central nervous system [3].

Study funding. The study was supported by the grant of the Russian Foundation for Basic Research No.19015-00195/19.

Conflict of interests. The authors have no conflict of interests to disclose.

\section{References}

1. Sergeyev P.V., Fedotcheva T.A., Rzheznikov V.M., Grinenko G.S., Semeykin A.V., Vetchinkina V.B., Atroshkin K.A., Shimanovsky N.L. A new russian gestagen with anticancer activity. Vestnik Rossiiskoi akademii meditsinskikh nauk 2007; 5: 27-32.

2. Sergeev P.V., Rzheznikov V.M., Korkhov V.V., Grinenko G.S., Semeikin A.V., Mayatskaya E.E. Shimanovskii N.L. Investigation of the gestagen activity of 17a-acetoxy-3ß-butanoyloxy-6-methylpregna-4,6-dien-20-one. Khimiko-farmatsevticheskii zhurnal 2005; 39(7): 2005; 39(7): 20-22.

3. Sheina N.I., Parshin V.A., Rybakov Yu.L., Gukasov V.M., Kostyaeva M.G., Semeikin A.V., Samoilikov R.V., Fedotcheva T.A., Shimanovskii N.L. Evaluation of the toxicity of new progestogen gestobutanoil in experiments on rats and mice. Eksperimental'naya i klinicheskaya farmakologiya 2018; 81(11): 18-25.

4. Rukovodstvo po ekspertize lekarstvennykh sredstv. T. I [Guidelines for the examination of medicines. Vol. I]. Moscow: Grif i K; 2013.

5. Stepanova E.S., Makarenkova L.M., Chistyakov V.V., Rybakov Y.L., Gukasov V.M., Fedotcheva T.A., Parshin V.A., Votyakov V.A., Shimanovskii N.L. HPLC-MS method for simultaneous quantification of innovative steroid drug and its metabolites in the blood sera of rats and rabbits. Khimikofarmatsevticheskii zhurnal 2018; 52(12): 75-79, https://doi. org/10.30906/0023-1134-2018-52-12-55-59.

6. Jordan A. Toxicology of depot medroxyprogesterone acetate. Contraception 1994; 49(3): 189-201, https://doi.org/ 10.1016/0010-7824(94)90037-x.

7. Schindler A.E., Campagnoli C., Druckmann R., Huber J., Pasqualini J.R., Schweppe K.W., Thijssen J.H. Classification and pharmacology of progestins. Maturitas 2003; 46(Suppl 1): S7-S16, https://doi.org/10.1016/j.maturitas. 2003.09.014.

8. Chen J., Zhang J.-W., Yang L., Li W. Structure 
elucidation of major metabolites from medroxyprogesterone acetate by P450. Chem Pharm Bull 2009; 57(8): 835-839, https://doi.org/10.1248/cpb.57.835.

9. Sturm G., Häberlein H., Bauer T., Plaum T., Stalker D.J. Mass spectrometric and high-performance liquid chromatographic studies of medroxyprogesterone acetate metabolites in human plasma. J Chromatogr 1991; 562(1-2): 351-362, https://doi.org/10.1016/0378-4347(91)80590-9.

10. Zeinalov O.A., Yaderets V.V., Stytsenko T.S., Petrosyan M.A., Andryushina V.A. Synthesis and biological activity of synthetic 17a-hydroxyprogesterone derivatives. Khimiko-farmatsevticheskii zhurnal 2012; 46(4): 7-10. 